\title{
Decision-Making in Extreme Situations Following the Fukushima Daiichi Accident
}

\author{
Sébastien Travadel
}

\begin{abstract}
The Fukushima Daiichi accident raises questions about current decision-making models. Faced with an overwhelming situation, which threatened both their own lives and that of the entire population, the plant's operators were obliged to take action, despite the lack of resources. In these conditions, decision making cannot be reduced to an optimization exercise based on a range of possibilities, or the application of planned operational responses to an emergency situation. The inevitable catastrophe, the social pressure it generates, the moral dilemmas it creates and the psychological drivers for action are characteristic of an extreme situation. The action plan must therefore be reinvented and individuals mobilised to these ends. It is therefore in a broader context of 'action' that decision making takes shape, and finds its logical foundations, meaning and temporality. Understanding decision making in extreme situations first requires a grasp of the development of a specific value system (that is mediated by the physical experience of the situation) in which the individual and social representations play a central role.
\end{abstract}

Keywords Decision-making - Extreme situations • Uncertainty • Ambiguity • Rationality • Temporality

\section{Introduction}

When Circe warned Odysseus about the dilemma he would face when passing through the Strait of Messina, she reminded him that it would be a decision of the heart. However, the priestess suggested that he choose the peril of Scylla: better to lose a few companions than to see them all engulfed by Charybdis. Odysseus followed this advice. Therefore, how can we say he 'decided'?

\footnotetext{
S. Travadel $(\bowtie)$

Centre for Research on Risks and Crises (CRC), MINES ParisTech,

PSL - Research University, Sophia Antipolis Cedex, France

e-mail: sebastien.travadel@mines-paristech.fr 
The word 'decision' typically refers to the "end of the deliberation in a voluntary act that results in the choice of an action". "The meaning given to each of these terms varies according to different schools of thought. In Aristotle's Nicomachean Ethics, the decision relates to the available resources needed to reach a given, desirable, conclusion, while Cartesians (e.g. René Descartes in his Metaphysical Meditations, 1641) would argue that without Circe's advice, Odysseus was taking a decision that was beyond his ability to understand and he therefore did not choose. Leibniz argues in his Theodicy (1710) that understanding is not a necessity-it only provides a guide - and that the decision exists only through the effort of action. In terms of expected utility theory [1], Odysseus rationally opted for the path that minimized the maximum damage.

Beyond these considerations, if the sacrifice of companions can be made acceptable, it must be integrated into a social and symbolic universe that gives it meaning. It is the will of the gods that allows Odysseus to return to his kingdom, which places him above other men. Of course, nowadays Man tends to be emancipated from the gods and can think for himself. He decides after careful reflection on causes, which "must always be mixed with chance in order to form a basis for reasoning". ${ }^{2}$ However, despite this distancing that is at the heart of Technology, the human being must still find meaning in their actions.

In his testimony [2], the Director of the Fukushima Daiichi power plant shows how operators, who were obliged to decide between the survival of some and the sacrifice of others, gave meaning to such decisions. Some of their critical decisions are set out below (Sect. 2). The inability of current theories to account for the magnitude of such decisions (Sect. 3) leads us to introduce the concept of 'projected time' (Sect. 4), and to explore mechanisms for the development of meaning in extreme situations (Sect. 5).

\section{Fukushima Daiichi: Faulty Decision-Making?}

It has become normal to describe the Fukushima accident as the result of poor decisions or a failure to act. ${ }^{3}$ In particular, the nuclear community has recognised that the accident could have been avoided through appropriate prevention measures. This would have entailed raising the height of the dykes that surrounded the site and protected it against waves following the results of numerical simulations, conducted in 2008, which indicated the potential for flooding. However, a consensus needs to be reached on the usefulness of such information: TEPCO indicated that it found

\footnotetext{
${ }^{1}$ Source: Dictionnaire culturel, A. Rey, Paris, Le Robert (2005).

${ }^{2}$ D. Hume, Of the Understanding. A Treatise of Human Nature. Book I, 1739.

${ }^{3}$ The Japanese Parliamentary Commission investigating the accident concluded that it was a 'man-made disaster' [3].
} 
the scenario unlikely given additional geological studies that invalidated the predictions [4].

Furthermore, how the accident was managed in the first days following the earthquake illustrates how decisions were taken in a context of crisis. The Japanese government's Investigation Committee was particularly interested in the circumstances in which Reactor 1 exploded on the afternoon of 12 March, 2011, when on-site teams thought they had vented it and cooling via the injection of seawater was about to begin [5]. Investigators asked the superintendent of the plant about his decision-making process given the information available to him [2]. To understand their approach, it is useful to recall certain facts.

On 11 March, the superintendent, Masao Yoshida, ordered preparations to begin for the injection of water into Reactor 1 using fire conduits and fire engines, to ensure cooling when the isolation condenser (IC) ${ }^{4}$ stopped working because of electrical failure. The water level in the tank was checked by reading an indicator. The level indication was normal, which supported the belief of operators that the reactor was correctly cooled. The level, however, could not be constantly monitored. At around 02:00 on 12 March, the indicator showed a stable or slightly rising water level, while at the same time the pressure inside the tank fell. Communication between the control room and the crisis room was difficult and the superintendent had not been informed of problems in the IC conduit. Perplexed by the rise in radioactivity, he concluded that the water level indicator was malfunctioning, that the IC had potentially been non-operational for several hours and that the core was probably exposed [2]. This was confirmed by measuring the increase in pressure in the containment vessel, which had exceeded its structural limits.

The plant's superintendent said that he regretted having placed too much confidence in the water level indicator and not having asked the control room about the IC conduit. For their part, investigators expressed their surprise at the apparent passivity of operators, given that an IC valve had been closed for no apparent reason and that the injection of water was impossible, with the result that the reactor was not cooled between 18:25 and 21:30. It appeared that none of the shift leaders had alerted the crisis cell.

Yoshida also stated that, "anyway, in terms of solutions, we did not have anything much better than the diesel pump, injecting with the fire pump and using the fire engine, which we finally did. Could we have reacted more quickly if we had known? I think that physically, we could not have gone faster" [2] (our translation).

Faced with pressure that exceeded the structural limits of the containment vessel, the superintendent asked for Reactor 1 to be vented. This operation required the activation of a valve, which proved particularly difficult and dangerous because of the high levels of radioactivity, the lack of electricity or pneumatic equipment, and the lack of indicators or light in the control room. As none of the operators had

\footnotetext{
${ }^{4} \mathrm{~A}$ backup system in some boiling water reactors. It cools the core when power cannot be evacuated by the main condenser. The system condenses the steam produced in a heat exchanger, and then re-injects it into the tank using gravity.
} 
taken the initiative and studied the plans and diagrams of the network in anticipation of venting, investigators asked Yoshida about when he had proposed this solution. He said that he had only considered venting when he had sufficient data to confirm that there was excess pressure in the chamber. The priority was therefore to obtain information on the key parameters indicating the state of the reactor [2].

The Commission was also surprised that operators had not considered the possibility of a hydrogen leak from the tank to the containment vessel into damaged pipes, although it was known that core fusion can produce large amounts of hydrogen. The Director said he had been aware that, if the core was damaged, hydrogen was produced; notwithstanding, he felt that it would remain confined within the vessel and he had focused on the threat of a container explosion, given the high pressure that had been observed. He stated, "the top of the reactor building is covered and ventilation panels are arranged on the side. We had not even imagined that these panels were closed and that hydrogen and oxygen had accumulated. We focused on the containment vessel. [...] We were prisoners of our a priori assumptions" [2] (our translation). Moreover, the entire international nuclear community was unaware of this scenario (Ibid.). It was only several hours after the explosion, following an investigation of the destroyed buildings, that operators concluded that the accumulation of hydrogen was probably the cause. They then studied the measures that needed to be taken in order to prevent a similar scenario at the plant's other reactors.

At dawn on 15 March, although Reactors 1 and 3 had already exploded, operators felt a strong jolt and heard a loud noise, which they could not immediately identify the source of; at the same time they noted damage to the building of Reactor 4 and that the pressure in the containment vessel of Reactor 2 had fallen to zero [5]. Although they gave little credibility to the reading from the pressure indicator and, on a scientific level, the hypothesis that Reactor 2 had exploded was not consistent with the available information, Yoshida considered the noise to be the most important factor and ordered an evacuation.

These examples suggest that the criteria for decision making, the relevance of the decision and the resources available to the decision maker were deficient, to the extent that they hindered the management of the accident. According to Yoshida himself, "it was total confusion. And that was in this atmosphere that it was necessary to give orders. So I recognize that it was not done in a logical and considered order" [2] (our translation). However, identifying potential derivations from logical reasoning and understanding the circumstances presupposes that the processes at work can be formalized.

\section{Testing Decision Models Using the Fukushima Daiichi Accident}

A classical approach in management science is to model decision-making in four phases. After collecting the information necessary to diagnose the problem, the decision maker formulates potential ways to resolve it, based on a necessarily 
limited rationality; they then select a particular mode of action, and evaluate a provisional satisfactory solution before iterating the process if necessary [6]. The comparison of potential scenarios results in mathematical formulations, developed from an economic perspective. The choice is equivalent to the optimization of a function (the utility). A set of axioms expresses postulates about the properties of preferences (for a discussion of the various theories see [7]). If an objective assessment of the probabilities of the consequences of an act is not possible, the decision maker can use 'subjective' probabilities. The probability distribution is therefore measured according to their knowledge of the possible states of the object they are interested in and upon which they wish to act.

Nevertheless, the assessment of subjective probabilities can be arbitrary and, in many practical situations, the behaviour of agents does not reflect preferences that are consistent with these axioms, without being necessarily called an 'error' [1]. To account for the assumed ignorance of the decision maker of certain states and their aversion to uncertainty, Gilboa and Schmeidler [8] showed that decisions can sometimes be seen as the maximization of a form of expected utility that takes into account the worst case scenario, which is consistent with the 'maxmin' model. It is also possible to broaden the spectrum of reactions in uncertain situations [9], in order to model less paranoid attitudes [1].

From this perspective, the behaviour of the decision maker is interpreted according to a concept of ambiguity relative to their knowledge of the worldcould not be sure of the meaning of the few information he got regarding the state of the facilities - , which is how the questions of the Japanese investigators should be understood (see Sect. 2). Faced with ambiguity about the state of Reactor 1, it could be argued that Yoshida violated expected utility theory by not deciding to immediately cool the core; or, alternatively, he demonstrated an aversion to uncertainty, by deciding to rely on information about the water level, while simultaneously preparing cooling mechanisms. ${ }^{5}$ The fact that he did not foresee hydrogen leaks can be interpreted in two ways using the 'maxmin' model: either he failed (cognitively) in his assessment based on all of the objective information available; or his attitude or imperfect knowledge led him to limit his choices to a subset of possible states. As for his decision to send staff to gather information on the state of the reactors before considering operations such as venting, this can be interpreted as an example of incomplete preference, where the status quo is maintained until such time as a conclusively better, new alternative appears.

Can we conclude that Yoshida acted irrationally, or do the models provide an incomplete description of such decisions? Gilboa [10] argues that we qualify behaviour as 'irrational' if whoever violates its precepts regrets their actions. The regret expressed by Yoshida about the confidence he placed in Reactor 1's water level indicators (see Sect. 2) would suggest that the decision was irrational.

\footnotetext{
${ }^{5}$ The superintendent had to manage limited resources and set priorities. Therefore, in this case it is not possible to apply a principle of dominance and conclude that the "ignore the water level" option was better.
} 
However, the superintendent immediately qualifies his comments by stating the impossibility of conceiving an alternative solution. Through this remark, Yoshida integrates his decision into a wider context of action.

This is to be compared with observations from current research in Natural Decision Making (NDM) that aims to account for decision making in the presence of changing conditions, ill-defined tasks, time pressure and significant personal risks in the case of error [11]. In these conditions, the decision maker's accounts of their decision making "do not fit into a decision-tree framework"; they are not "making choices", "considering alternatives", or "assessing probabilities", but they see themselves as acting and reacting on the basis of prior experience, generating and modifying plans to meet the needs of the situation [12]. The decision maker acts on the basis of heuristics, then develops a mental simulation to assess the feasibility of the proposed response. These studies are consistent with those of Gilboa and Schmeidler [8], who axiomatized a Case-Based Decision Theory, which postulates that the decision maker acts by comparing the current situation to one already experienced. ${ }^{6}$ Coordination and leadership modalities also change when tasks are unpredictable and interdependent, as is the case in an emergency context [13].

However, if the context for the intervention of firefighters or emergency room surgeons is sometimes called an 'extreme situation' [14], in practice these 'dynamic' situations constitute the predictable working environment of the decision maker. The problem relates more to the definition of the case in question, than the solution once the diagnosis has been made. Ultimately, the 'extreme' nature of a situation is assessed differently by different researchers and does not necessarily imply that the decision maker is completely overwhelmed or out of their depth [15]. Such individuals have substantial resources at their disposal, a well-established set of procedures and the impact of their actions is limited at the scale of society.

In addition, whether they focus on decision making processes based on scenarios or on more empirical approaches, investigations of the influence of stress [16], a hostile physical or social environment [17], or the formal organization [18] on the performance of the decision maker are simplistic. They lead the analysis to be focused on the physical or emotional factors that could have led Yoshida to make errors (for example his decision to evacuate the site). This cognitive approach is indicative of the common sense meaning of 'emotion', i.e. a complex state of consciousness, usually sudden and momentary, accompanied by physiological disorders. ${ }^{7}$

However, this perspective largely ignores the role played by emotions in decision making [19]. Ellis [20] considers that emotions and values are necessary components of a decision, which does not mean that the decision becomes 'irrational'. This assertion is illustrated by the way in which the plant's staff decided to return to the field following the explosion at Reactor 3 on 15 March. According to

\footnotetext{
${ }^{6}$ However, this theory is not specific to an emergency situation.

${ }^{7}$ Dictionnaire culturel, op. cit.
} 
Yoshida, "everyone was in shock, frozen, unable to think. So I got them all together to talk to them. [...] I also told them [...] that if we did not respond, the situation would become even more catastrophic [...] It was at that point that I experienced one of the most emotional moments of my life. They all wanted to go back, they even pushed each other out of the way to get there" [2] (our translation).

The Fukushima accident demonstrates how difficult it can be to make decisions when the realities of the situation are not conducive and the unfolding scenario cannot be stopped (due to a serious lack of resources); at the same time, the physical integrity of individuals cannot be guaranteed and the consequences of taking action - or not-have societal significance. The inevitable catastrophe, the social pressure it generates, the moral dilemmas it creates and the psychological drivers for action are characteristic of an extreme situation, as described by Travadel and Guarnieri [21]. In extreme situations, the action plan must be reinvented and individuals mobilised to this end. Yoshida therefore stated that he initially had no solutions, no idea how to react, and fell back on 'administrative' procedures in an attempt to regain self-confidence [2]. Similarly, organizational theory tends to regard a crisis as a situation where, "not only are there insufficient resources, but it is a situation where the rules were not thought of yet" [22]. The new order must be acceptable, when life itself - that of workers or of an entire population - is threatened.

Current models do not make it possible to deepen our understanding of the practical management of such situations. To progress, the analysis must be based on suitable metaphysics and integrate the world of the decision maker, in which their decisions make sense. The following sections consider these two dimensions.

\section{Decision Making and Catastrophe: Back from the Future and Return}

The concept of decision making inevitably refers to concepts of causation and rationality. Through the introduction of probabilistic links between states of the world and actions, expected utility theories opened up the debate on the causal link. Savage's axioms (for a discussion, see [7]) apply to actions that do not have a causal influence on the state of the world in which their consequences are experienced. ${ }^{8}$ Consequently, the final state of the system is often associated with a fixed point, ${ }^{9}$ which rules out many decision-making scenarios. To overcome this problem, (unconditional) utility was replaced by a concept of utility which conditions the probabilities of states of the world (those leading to the expected consequences) to the execution of the act. These probabilities are interpreted either in terms of classical conditional probabilities, or causal probability [23]. In the first case,

\footnotetext{
${ }^{8}$ The problem can be reformulated to make it the case [23].

${ }^{9}$ This is the case in economic models such as the 'perfect competition' model in which the actions of one agent do not change the overall balance.
} 
evidential decision theory computes an act's expected utility using the probability of a state given the act $\mathrm{P}(\mathrm{S} \mid \mathrm{A})^{10}$; in the second case, causal decision theory replaces $\mathrm{P}(\mathrm{S} \mid \mathrm{A})$ with $\mathrm{P}(\mathrm{A} \rightarrow \mathrm{S})$ or a similar causal probability [24]. This choice defines the decision making perspective. Thus, according to Jeffrey, "in decision-making it is deliberation, not observation, that changes your probabilities. To think you face a decision problem rather than a question of fact about the rest of nature is to expect whatever changes arise in your probabilities for those states of nature during your deliberation to stem from changes in your probabilities of choosing options" [25].

Rationality is therefore at least dual, and Lewis's counterfactual decision theory can account for both aspects [26]. The fundamental idea of this analysis is that the counterfactual "If A were the case, $C$ would be the case" is true just in case it takes less of a departure from actuality to make the antecedent true along with the consequent than to make the antecedent true without the consequent [27]. The causal dependence is then stated as follows: Where $\mathrm{c}$ and e are two distinct actual events, e causally depends on $\mathrm{c}$ if and only if, if $\mathrm{c}$ were not to occur, e would not occur.

A dual rationality goes hand-in-hand with the concept of temporality. Either the decision maker operates by projecting a set of possible futures and seeks to maximize the consequences of their actions, or they try to make their actions as consistent as possible with a desirable state of the world. Dupuy [28] thus states that: either, at every moment in 'occurring time', regardless of the predictions of an infallible Predictor, "agents have the power to act in such a way that, if they were so to act, they would render inaccurate the predictions of the supposed Predictor", which means that causal links are probable ones; or, at all times in 'projected time', causal links are fixed and the agent has the power to do something such that, if he were to do it, the 'script' of his life would have been different. Dupuy suggested merging these two concepts of temporality form a loop, in which the past and the future determine each other. In particular, a future state, when represented by a favourable probability and another that is disastrous (with a very low probability) can serve as an anchor point for ongoing action in an approach that is constantly under review [26].

We argue that Yoshida was guided by these two representations of temporality. He applied a causal type of reasoning in order to deduce from the information at his disposal that the core of Reactor 1 was undergoing fusion. He expected to find proof of an 'event e', for which it was then necessary to find the cause. Using the same reasoning (this time in anticipation) he decided to start the venting manoeuvre and avoid an explosion, based on the objective data available to him. Given the information at his disposal, he assessed the plausibility of a causal link to unwanted consequences, based on an appreciation of the law of physics. At the same time, he organized actions to be taken based on information that he did not yet have in a measurable form, but which he had nevertheless convinced himself was true.

\footnotetext{
${ }^{10}$ This theoretical orientation has led to debate about the ability of an agent to assess the likelihood of their actions - a problem that is resolved by invoking the predisposition of the agent to act [23].
} 
Although it had not yet happened, the future catastrophe seemed real enough to him to guide his actions. The destruction of an entire region-not simply an official accident - constituted, at least a partial anchor point for the decisions that he took. He repeated this point many times during the hearing, "it was clear that we were heading for a major accident and we had to prepare for it" [2] (our translation). He stated that he had always had such a situation at the back of his mind, beginning with his initial instructions to prepare alternative cooling methods. Yoshida's decisions therefore took place in a sort of 'projected time' temporality. It would therefore be wrong to say that he 'expected' the loss of the cooling systems, as this would place his actions in a causal type of rationality and an 'occurring time' temporality. This idea is similar to that of Dupuy [28], who argues that temporality should not be seen as a container in which human activities take place, but as a result of human activities.

This observation may seem trivial. Naturally, where the cooling systems of a nuclear reactor are damaged, the operator must consider the potential for disaster. However, limiting the investigation to the critical bifurcations of the decisions as the situation unfolded, and trying to understand the rationality of choices based on available information or resources - an exercise that is at the heart of traditional investigation processes - means that the disaster is only looked at in terms of its potential, which is likely to significantly weaken its power of determination. A contrario, when rationality is viewed in terms of 'projected time' it "is a fundamental existential problem that rears its head every time we are confronted with absolute uncertainty concerning a variable on which our 'salvation' depends" [28]. By comparison, an approach in terms of scenarios sees the future as a distant objective reality for the individual. In this context, the paradox highlighted by Dupuy [26] is as follows: prospective methods make it possible to socially create an image of the future; at the same time, they empty it of its physical dimension, they do not acknowledge reality of any kind.

Difficulties arise when the decision is counterfactually examined using a probabilistic-causal approach, with a view to arriving at a moral judgment. The expression of a causal link is inherently relative. Core fusion, overpressure or leaks in the containment vessel of Reactor 1, like the accumulation of hydrogen and the failure of ventilation equipment, may be considered as the 'causes' of the explosion of Reactor 1. Emphasising one over the other is relevant depending on the class of situation in question, the context or the contrast to be established between a situation and an event. For this reason some authors have suggested the reformulation of the counterfactual causal dependence as follows: If $c^{*}$ had occurred instead of $c$, then $\mathrm{e}^{*}$ would have occurred instead of e [27]. Whichever is the case, this observation shows that causality has no transcendent reality, except in the narrow field of science (i.e. excluding human affairs). An assertion of causality requires adopting a point of view, the mark of subjectivity. The a posteriori allocation of probabilities in causal reasoning leads to short-circuiting the infinity of potential future bifurcations, and the retention of only a few of them. Reasoning is thereby biased because, unlike moral judgments, "the foundation for probabilistic judgment cannot include any information that is only available after action has been taken" [26] (our 
translation). This may explain the discrepancies between the questions of the investigators and the action taken by Yoshida (see Sect. 2). The Commission's investigators mixed two interpretations: their causal analysis in an 'occurring time' frame (reconstructed a posteriori) support a value judgments of the actions taken by the plant's superintendent. This approach does not take full account of the decisions made at Fukushima Daiichi. To make sense, Yoshida's actions must be understood in their entirety; it is impossible to separate decisions from the close connection that the individual has with the realities they confront. When it comes to give it meaning, action in extreme situation emerges at least in part within a 'projected time' temporality.

\section{From Decision Making to Taking Action in Extreme Situations}

The plant's superintendent was unambiguous in his description of the relationship between his staff and the production facility, which he characterised as a fight, dominated by fear and suffering. His lexicon and register provide further evidence: he speaks of "three monsters", "three nuclear units that were unleashed", and tries to "achieve the impossible with very few staff" to "tame this thing" [21] (our translation). In this context of sensory stimulation, impressions and perceptions had a strong influence on his decisions. His order to evacuate the site is an example of this (see Sect. 2).

However, emotions do not always disrupt the ambient order and well-regulated planning. Damasio [29] showed that they are a key component in the development of rational thinking. Several experiments have since confirmed the need to reintroduce emotion into the process of conceptualization. Similarly, it has been demonstrated that individuals produce concepts according to their perceptual experience [30]. Such studies show that the embodiment of emotion can ground concepts. An illustration of this is found in Yoshida's testimony. He stated that following the explosion of Reactor 1 (when the pressure was about $500 \mathrm{kPa}$ ), the number '500' left him "ill at ease". He went on to add, "I know this is totally irrational, it was just a feeling" [2] (our translation); this feeling would influence his decisions concerning the other reactors.

Leontyev [31] put forward similar arguments. He claimed that human activity forms the foundation for consciousness - a back-and-forth process that operates between an individual and an object, guided by a pattern and determined by sensual contact with the outside world. Leontyev goes on to say that beyond this circular process, which influences interactions between the organism and the environment, mental representations of the objective world are governed by processes in which the individual is in physical contact with it and thereby obeys its intrinsic properties and its own relationships. It is the object that initially determines how actions unfold and, secondly, it is how it appears as a subjective product of the action that 
records and stabilizes the objective content of the activity. The resistance of the object breaks the cycle of internal mental processes and provides an opening to the outside world. Moreover, Vygotsky [32] showed that actions are social by nature; they always take place in the presence of others and are mediated by signs. Recent studies characterize the moderating role of social relations in the relationship between the individual and their body as a conceptualization tool: the "current (social or other) context influences the way in which a concept is represented in a conceptual task and the extent people recruit embodied information to solve it" [30].

According to these theoretical results, meaning is grounded in bodily processes of perception and action. The organism's bodily interaction with the environment is of crucial importance to its cognitive processes [33]. What is meant here by the 'body' is not the body as a functional system with input and output, but rather, as the enactive approach defines it, "an adaptive autonomous and therefore sensemaking system" [34]. From an anthropological perspective, Mauss had already defined the body as the "primary technical object" [35], which appears therefore as a support and provides meaning. "It is impossible for a man not to be permanently changed and transformed by the sensory flow that runs through him. The world is the product of a body which translates it into perceptions and meaning, one cannot exist without the other. The body is a semantic filter" [36] (our translation).

From this perspective, phenomenology, which is specific to the experiential aspect of emotion, can be linked to values. Here, 'values' represents what gives meaning to action, although not exclusively as an abstract object to consciously work towards. At a more primitive level, 'values' are more properties of a particular type that are exemplified by contexts, objects or behaviours: emotions-such as fear-link us with exemplifications of these evaluative properties - for example danger [37]. In an emotional state, the body becomes prepared to potentially take action and "the specific way it is prepared is interpreted, very naturally, as an apprehension of some of the evaluative aspects of the environment. Here, then, bodily sensations are not understood as simply the effect of thinking about the environment, they play a direct role, by virtue of their phenomenology, as an explicit presentation of their own objects, i.e. values. Emotions are what is felt by a body that is prepared for action: it is therefore in this narrow sense that one can say that emotion is an experience of value" (ibid., our translation).

Plunged into an unprecedented sensory universe, the operators at Fukushima Daiichi had to redefine the meanings and values in their world. The scene was apocalyptic: high levels of radioactivity, extreme temperatures, piles of debris, aftershocks, floods, darkness and exploding reactors formed the context in which they were required to take action. Decision making was shaped by their contact with this material and social reality, physical challenges, and the way they behaved and saw others behaving.

Individual commitment was influenced by the need to take action and the resources required, the rules and shared representations of the action to be performed. Group behaviour is indeed determined by the image it has of its task [38]. In extreme situations, the construction of this image integrates current social 
representations from the public sphere. In this case, public opinion of the Fukushima Daiichi accident hinged on interference from the Prime Minister in the management of the crisis and the incompetence of TEPCO [39]. The validity of the actions taken by on-site operators was not acknowledged until long after the events of 11 March, 2011. Three months after the accident, workers suffered from an unusually high level of psychological problems, linked to the social discrimination they were subject to [40].

The decisions of the plant's superintendent were therefore influenced by the need to protect the physical and mental wellbeing of his colleagues [2]. Nevertheless, when it became clear that the only way to vent Reactor 1 and prevent its explosion was to manually open a valve located in a highly radioactive zone, technicians reported for work. The superintendent stated, "We decided to do the operation by hand, as a last resort. We decided to do this because we thought that it could be done, if all it took was to accept being irradiated" (ibid., our translation). It could have been the case that economic considerations dictated this decision: the loss of a few employees could have brought a solution to the crisis as long as it would not have jeopardized the remaining resources. However, such a decision can only be seen as acceptable as a result of a personal and interpersonal journeys of the decision maker and his colleagues, through an action process leading to a singular system of values. In order to understand decision making in extreme situations, one must first understand the development (mediated by physical experience of the situation) of this value system in which individual and social representations play a key role.

\section{Conclusion}

Investigations into the accident at Fukushima Daiichi highlighted failures in communication, and a lack of foresight and anticipation on the part of operators in some of the decisions that were taken. These analyses implicitly suggest that there was a range of options based on a known state, and they reduce decision making to an optimization exercise. Consequently, the feedback from experience becomes focused on the lack of coordination between the operator's headquarters, the Japanese government and the plant, obsolete instrumentation, or the effects of stress on behaviour. ${ }^{11}$ Of course it is clear that our understanding of the impact of stress or emotions on behaviour or decision making is still preliminary [41], and merits further examination. However, paradoxically, this type of 'safety science' approach seeks to place behaviour in a theoretical context made up of bloodless social mechanisms that take no account of the humanity of those who must act. Moreover, in the nuclear context, executives are sometimes tempted to resort to formalisms to demonstrate a high degree of control, even if it means negating the difficulties faced

\footnotetext{
${ }^{11}$ See for example the conclusions of the Japanese Parliamentary Investigation Commission [3].
} 
by operators [42]. In extreme conditions, the risk is that the factors that determine the 'entry into resilience' are ignored [43].

In their current state, the lessons that have been learned from the accident may hide some key drivers for the planning and development of actions taken in the face of devastation. The concept of the extreme situation invites us to supplement these lessons and reintroduce factors related to the human body, emotions, and kinaesthetic, which create our initial relationship with the world, and constitute a socio-sensual structure for behaviour. In order to understand behaviour in extreme situations we must first understand the experience, which is marked by radical changes that cannot be easily aggregated into logical arguments. Moreover, the integration of a more sensitive approach to the behaviour of others into an otherwise rational approach to decision making would appear to be a promising avenue for better management [44].

On-site management problems were compounded by the injunctions of remote decision makers. The conflict between the plant's staff and the Japanese government cannot simply be reduced to a failure to share information or a lack of awareness of each other's problems. It is the result of different relationships with danger, through social pressure, to moral issues. More generally, the management of the accident demonstrates the intrinsic limit of an "optimization" type decision making process. At the political level, there is a tendency to expect from rational decision maker to base their decision on technical consideration, whereas it has some necessary social and ethical implications which cannot be avoided. In any event, the people rely on their own criteria in order to assess the rationality of an evacuation for instance, based on the social meaning of their decision, personal feelings, etc. A 'resilient community' is the result of these multiple nucleus of action/decision which have to be coordinated with a full acknowledgement of their specificities.

It is therefore necessary to establish an ethical framework that is appropriate to extreme situations, which articulates different temporal and rational registers. The intervention by the residents of Olympus offers a universal interpretation of Odysseus's decision. A contrario, due to the fact that all parties sought to make their own sense of the situation, the Japanese population, its government and authorities did not understand the magnitude of Yoshida's actions or those of his colleagues.

\section{References}

1. I. Gilboa, M. Marinacci, Ambiguity and the bayesian paradigm, in Advances in Economics and Econometrics. Tenth World Congress, ed. by D. Acemoglu, M. Arellano and E. Dekel, vol. 1 (Cambridge University Press, 2013), p. 179-242

2. F. Guarnieri, S. Travadel, C. Martin, A. Portelli, A. Afrouss, L'accident de Fukushima Daiichi: le récit du directeur de la centrale. vol. I, L'anéantissement, (Presses des Mines, Paris, 2015), p. 341

3. NAIIC, The Official Report of The Fukushima Nuclear Accident Independent Investigation Commission. Executive Summary, The National Diet of Japan (2012) 
4. H. Drumhiller, International Experts' Meeting on How did Individual and Organizational Use of Probability and Risk Assessment at TEPCO Contribute to the Fukushima Accident? presented at Human and Organizational Factors in Nuclear Safety in the Light of the Accident at the Fukushima Daiichi Nuclear Power Plant, Vienna, 21-mai-2013 2000, International Atomic Energy Agency (2000)

5. A. Portelli, A. Afrous, L'accident nucléaire de Fukushima Daiichi: rappel des faits, in L'accident de Fukushima Daiichi: le récit du directeur de la centrale ed. by F. Guarnieri, S. Travadel, C. Martin, A. Portelli, A. Afrouss, vol. I, L'anéantissement, p. 53-68

6. J.G. March, H. Simon, Organizations, 2nd edn. (Wiley-Blackwell, Cambridge, 1993)

7. P.C. Fishburn, Utility Theory for Decision Making (Wiley, New York, 1970)

8. I. Gilboa, D. Schmeidler, Case-based decision theory. Q. J. Econ. 110(3), 605 (1995)

9. P. Ghirardato, F. Maccheroni, M. Marinacci, Differentiating ambiguity and ambiguity attitude. J. Econ. Theory 118(2), 133 (2004)

10. I. Gilboa, Rationality and the Bayesian Paradigm: An Integrative Note (2014), http://itzhakgilboa. weebly.com/uploads/8/3/6/3/8363317/gilboa_rationality_and_bayesian_paradigm.pdf. Accessed May 2015

11. G. Kelin, K. Klinger, Natural decision making, Hum. Syst. IAC Gatew, XI(3), 16 (2000)

12. G.A. Klein, A recognition-primed decision (RPD) model of rapid decision making, in Decision Making in Action: Models and Methods, ed. by G.A. Klein, J. Orasanu, R. Calderwood (Ablex Publishing Corporation, Norwood, 1993), p. 138-147

13. K.J. Klein, J.C. Ziegert, A.P. Knight, Y. Xiao, Dynamic delegation: Shared, hierarchical, and deindividualized leadership in extreme action teams. Adm. Sci. Q. 51(4), 590 (2006)

14. J.-F. Lebraty, P. Lievre, M. Recope, G. Rix-Lievre, Stress and Decision. The role of experience, in Proceedings of 10th International Conference on Naturalistic Decision Making (University of Central Florida, Orlando, Florida, 22 May-3rd June 2011), p. 266-270

15. C. Gode-Sanchez, V. Hauch, M. Lasou, J.-F. Lebraty, Une singularité dans l'aide à la décision: le cas de la Liaison 16. Systèmes Inf. Manag. 17(2), 9 (2012)

16. M.A. Staal, Stress, Cognition, and Human Performance: A Literature Review and Conceptual Framework, NASA/TM-2004-212824, NASA Ames Research Center (2004)

17. A. Strommen-Bakhtiar, E. Mathisen, Sense-giving systems for crisis situations in extreme environments, in Proceedings of InSITE 2012, (Informing Science Press, Montréal, 22-27 June 2012), p. 91-112

18. G.A. Bigley, K.H. Roberts, The incident command system: High reliability organizing for complex and volatile task environments. Acad. Manage. J. 44(6), 1287 (2001)

19. G. Loewenstein, J.S. Lerner, The role of affect in decision making, in Handbook of Affective Science ed. by R.J. Davidson, K.R. Scherer, H.H. Goldsmith, (Oxford University Press, New York, 2003), p. 619-642

20. G. Ellis, The myth of a purely rational life. Theol. Sci. 5(1), 87 (2007)

21. S. Travadel, F. Guarnieri, L'agir en situation extrême, in L'accident de Fukushima Daiichi: le récit du directeur de la centrale ed. by F. Guarnieri, S. Travadel, C. Martin, A. Portelli, A. Afrouss. vol. I (L'anéantissement, Presses des Mines, Paris, 2015), p. 283-321

22. G. de Terssac, Théorie du travail d'organisation, in Interpréter l'agir. Un défi théorique ed. by B. Maggi, (PUF, Paris, 2011), p. 97-121

23. J. Joyce, Causation in decision theory, presented at Causality Study Fortnight 09-sept-2008, University of Kent (2008)

24. P. Weirich, Causal decision theory, The Stanford Encyclopedia of Philosophy. Winter 2012 Edition, 05-oct-2012. [online]. http://plato.stanford.edu/archives/win2012/entries/decisioncausal/. Accessed 15 May 2015

25. R. Jeffrey, Subjective Probability: The Real Thing (Cambridge University Press, Cambridge, 2004)

26. J.-P. Dupuy, Pour un catastrophisme éclairé (Seuil, Paris, 2004)

27. P. Menzies, Counterfactual theories of causation, Stanford Encyclopedia of Philosophy Archive. Spring 2014 Edition, 10-janv-2001. [online]. http://plato.stanford.edu/archives/ spr2014/entries/causation-counterfactual/. Accessed 15 May 2015 
28. J.-P. Dupuy, Two temporalities, two rationalities: a new look at Newcomb's paradox, in Economics and Cognitive Science, P. Bourgine, B. Walliser, ed. by Pergamon (London, 1992), p. 191-220

29. A. Damasio, The Feeling of What Happens: Body and Emotion in the Making of Consciousness (Mariner Books, San Diego, 2000)

30. P.M. Niedenthal, P. Winkielman, L. Mondillon, N. Vermeulen, Embodiment of emotion concepts. J. Pers. Soc. Psychol. 96(6), 1120 (2009)

31. A.N. Leontiev, Activity and consciousness, in Philosophy in the USSR, Problems of Dialectical Materialism (Progress Publishers, Moscow, 1977), p. 180-202

32. L. Vygotsky, Mind in Society (Harvard University Press, Cambride, 1978)

33. R. Kerkhofs, W.F. Haselager, The embodiment of meaning. Manuscrito 29, 753 (2006)

34. E.A. Di Paolo, E. Thompson, The enactive approach, in The Routledge Handbook of Embodied Cognition, ed. by L. Shapiro (Routledge, New York, 2014), p. 68-78

35. M. Mauss, Les techniques du corps. J. Psychol. 32(3-4), 365 (1936)

36. D. Le Breton, Anthropologie du corps et modernité, (PUF, Paris, 2013)

37. J.A. Deonna, F. Teroni, L’intentionnalité des émotions : du corps aux valeurs, Rev. Eur. Sci. Soc. XLVII(144), 25 (2009)

38. S. Moscovici, G. Paichelier, Travail, individu et groupe, in Introduction à la psychologie sociale, vol. II (Librairie Larousse, Paris, 1973), p. 9-44

39. K. Cleveland, Significant breaking worse. Crit. Asian Stud. 46(3), 509 (2014)

40. J. Shigemura, T. Tanigawa, I. Saito, S. Nomura, Psychological distress in workers at the fukushima nuclear power plants. JAMA 308(7), 667 (2012)

41. K.M. Kowalski-Trakofler, C. Vaught, T. Scharf, Judgment and decision making under stress: an overview for emergency managers. Int. J. Emerg. Manag. 1(3), 278 (2003)

42. C. Dejours, Pathologie de la communication, situations de travail et espace public : le cas du nucléaire, in Raisons Pratiques, 3, ed. by A. Cottereau, P. Ladriere, (Éditions de l'Ecole des Hautes Etudes en Sciences Sociales, Paris, 1992), p. 177-201

43. F. Guarnieri, S. Travadel, Engineering thinking in emergency situations: A new nuclear safety concept. Bull. At. Sci. 70(6), 79 (2014)

44. D. Van Hoorebeke, L'émotion et la prise de décision, Rev. Fr. Gest. 34(182), 33 (2008)

Open Access This chapter is licensed under the terms of the Creative Commons Attribution 4.0 International License (http://creativecommons.org/licenses/by/4.0/), which permits use, sharing, adaptation, distribution and reproduction in any medium or format, as long as you give appropriate credit to the original author(s) and the source, provide a link to the Creative Commons license and indicate if changes were made.

The images or other third party material in this chapter are included in the chapter's Creative Commons license, unless indicated otherwise in a credit line to the material. If material is not included in the chapter's Creative Commons license and your intended use is not permitted by statutory regulation or exceeds the permitted use, you will need to obtain permission directly from the copyright holder.

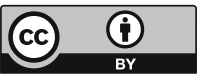

